\title{
Genetic and Molecular Characterization of Leaf Rust Resistance in Two Durum Wheat Landraces
}

\author{
Naeela Qureshi, Harbans Bariana, James A. Kolmer, Hanif Miah, and Urmil Bansal ${ }^{\dagger}$
}

First, second, fourth, and fifth authors: The University of Sydney Plant Breeding Institute, Private Bag 4011, Narellan, NSW 2567, Australia; and third author: United States Department of Agriculture-Agricultural Research Service Cereal Disease Laboratory, St. Paul, MN, 55108. Accepted for publication 13 June 2017.

\begin{abstract}
Leaf rust, caused by Puccinia triticina, is a constraint to durum wheat (Triticum turgidum subsp. durum) production, and landraces are reported to be an important source of resistance. Two Portuguese landraces (Aus26582 and Aus26579) showed resistance against durum-specific P. triticina races and were crossed with a susceptible landrace (Bansi) to develop recombinant inbred line (RIL) populations. Monogenic segregation for leaf rust resistance was observed among both RIL populations. The underlying locus, temporarily named $L r A W 2$, was mapped to the short arm of chromosome 6B in the Aus26582/Bansi population and five DArTseq markers cosegregated with $\operatorname{LrAW2}$. Simple sequence repeat markers sun683 and sun684, developed from the chromosome survey sequence (CSS) contig 6BS_2963854, identified through BlastN search of cosegregating DArTseq
\end{abstract}

ABSTRACT markers in the International Wheat Genome Sequencing Consortium database, cosegregated with $L r A W 2$. Comparison of the CSS contig 6BS_2963854-based sequences amplified from parental genotypes led to the development of marker sunKASP_60, which also showed close linkage with LrAW2. Markers sun684 and sunKASP_60 showed close association with $L r A W 2$ in both RIL populations. The amplification of $L r A W 2$-specific products by linked markers in Aus26582, Aus26579, and Guayacan ( $L r 61)$ indicated that $L r A W 2$ may be $L r 61$. The alternate amplicon or haplotype produced with LrAW2-linked markers in Australian durum cultivars demonstrated their effectiveness in marker-assisted selection.

Additional keywords: breeding, genetic analysis, pyramiding, SNP.
Durum wheat (Triticum turgidum L. subsp. durum, $2 \mathrm{n}=4 \mathrm{x}=28$ ) is the commonly cultivated tetraploid wheat, especially in the Mediterranean region, which contributes $50 \%$ to the total global durum production (Henkrar et al. 2016). It is mostly used for making pasta, flat bread, and couscous in many regions of the world. The sustainability of durum wheat production is challenged by many abiotic and biotic stresses. Leaf rust, caused by Puccinia triticina, is among the important biotic stresses and in the event of severe epidemics up to $70 \%$ reduction in durum wheat production can occur (Herrera-Foessel et al. 2006; Singh et al. 2004).

Durum wheat showed a high level of leaf rust resistance against commonly prevailing $P$. triticina races (Ordoñez and Kolmer 2007a) until the detection of durum-specific races of $P$. triticina in Mexico (Singh et al. 2004). In 2001, appearance of the P. triticina race BBG/BN in northwestern Mexico carrying virulence to Altar C84, which carries $L r 72$, defeated resistance in CIMMYT durum wheat cultivars known to be resistant for over 25 years and caused economic losses of approximately US $\$ 32$ million (Herrera-Foessel et al. 2014; Singh et al. 2004). In 2003, the race BBG/BN was observed on durum wheat in southern California (Kolmer et al. 2007). At the same time, changes in virulence of $P$. triticina on durum wheat were also observed in Spain (Martinez et al. 2005) and France (Goyeau et al. 2006, 2012). Goyeau et al. (2012) stated that the detection of the Altar C84-virulent race in France in 1997 predated its emergence in Mexico. Phenotypic analysis and simple sequence repeat (SSR) genotyping of predominant durum-specific P. triticina races collected from North America, South America, Western Europe, and the Middle East indicated a high level of genetic similarity, whereas races collected from Ethiopia were genetically distinct and indicated a different origin (Kolmer 2005;

†Corresponding author: U. Bansal; E-mail: urmil.bansal@sydney.edu.au

C 2017 The American Phytopathological Society
Kolmer and Acevedo 2016; Kolmer and Hughes 2014; Ordoñez and Kolmer 2007b).

Of more than 70 designated leaf rust resistance genes (McIntosh et al. 1995, 2013, 2014), very few are known to be present in durum wheat cultivars. Following the detection of durum-specific $P$. triticina races in Mexico, CIMMYT scientists initiated genetic analysis of leaf rust resistance among durum wheat germplasm, and this led to the postulation of complimentary gene pair $L r 27+L r 31$ located in chromosomes 3BS and 4BS, respectively (Singh et al. 1993; Singh and McIntosh 1984), Lr3a in chromosome 6BL (Browder 1980), Lrl4a in chromosome 7BL (Dyck and Samborski 1970), Lr23 in chromosome 2BS (Watson and Luig 1961), Lr61 in chromosome 6BS (Herrera-Foessel et al. 2008), and $L r 72$ in chromosome 7BS (Herrera-Foessel et al. 2014). Loladze et al. (2014) showed the presence of some of these genes in the elite CIMMYT germplasm and discussed a complicated linkage or allelic relationships among genes located in chromosome 6BS. Other resistance genes found only in durum wheat cultivars include LrCamyo in chromosome 6BL (Herrera-Foessel et al. 2007) and LrWo in chromosome 5BS (Singh et al. 2010). Lr3a, Lr14a, Lr23, and $L r 27+L r 31$ are also present in common wheat but are ineffective against predominant common wheat $P$. triticina races (McIntosh et al. 1995). However, $\operatorname{Lr} 23$ is effective against the currently predominating $P$. triticina races in Australia (Chhetri et al. 2017).

Identification and characterization of genetically diverse sources of leaf rust resistance are essential to control this disease. Durum wheat landraces were cultivated until the mid-20th century (Soriano et al. 2016). The cultivation of landraces was replaced by improved semidwarf cultivars (Lopes et al. 2015), thus leaving behind some unused genetic diversity. Recent studies clearly demonstrated the potential of landraces to contribute diverse alleles for economic traits (Bansal et al. 2013; Bariana et al. 2013; Soriano et al. 2016). Two durum wheat landraces (Aus26582 and Aus26579) collected from Portugal (Miller et al. 2000) exhibited resistance against durum-specific $P$. triticina races (U. Bansal and H. Bariana, unpublished). This investigation was planned to conduct genetic 
analysis of leaf rust resistance carried by Aus26582 and Aus26579, to determine genomic locations of underlying resistance genes, and to identify molecular markers closely linked with resistance genes.

\section{MATERIALS AND METHODS}

Plant materials. Aus26582 and Aus26579 collected from Portugal were kindly supplied by the Australian Winter Cereal Collection, Tamworth, NSW, Australia (now the Australian Grains Gene Bank, Horsham, VIC, Australia). These landraces were crossed with the susceptible landrace Bansi from India to generate recombinant inbred line (RIL) $\mathrm{F}_{5: 6}$ populations comprising 155 and 79 lines, respectively. Eleven Australian durum cultivars were used to test the effectiveness of linked markers for marker-assisted selection (MAS).

Pathogen materials. Durum-specific $P$. triticina races CA 1.2 and ETH 12.5-2 from California and Ethiopia, respectively, were used for testing both RIL populations (Aus26582/Bansi and Aus26579/Bansi) at the Cereal Disease Laboratory (CDL), St. Paul, MN. Aus26582, Aus26579, and Bansi were also tested against six Australian P. triticina races: 104-2,3,6,(7) (Plant Breeding Institute culture number 231), 10-1,2,3,4 (348), 68-1,2,3,4 (469), 104-1,(2),3,(6),(7),11,13 (547), 76-1,3,5,7,9,10,12+Lr37 (621), and $104-1,3,4,6,7,8,9,10,12+\operatorname{Lr} 37(634)$ from the cereal rust race collection of the University of Sydney Plant Breeding Institute, Cobbitty. The virulence or avirulence details of $P$. triticina races are given in Table 1 .

Greenhouse screening. Evaluation against durum-specific P. triticina races. Seedling leaf rust tests were carried out on Aus26582/Bansi and Aus26579/Bansi RIL populations along with the parents Aus26582, Aus26579, and Bansi at the CDL. The RIL populations were planted in $3.5-\mathrm{cm}^{2}$ plastic pots, with 5 to 6 seeds/ RIL and four RILs per pot planted in the quarterly corners that were filled with vermiculite and placed in plastic trays as six pots per tray. When the primary leaves were fully expanded, seedlings of the RILs, parents, and common wheat 'Thatcher' were inoculated with races CA1.2 and ETH 12.5-2. For seedling inoculations, approximately $1 \mathrm{mg}$ of urediniospores was mixed with $0.2 \mathrm{ml}$ of Soltrol 170 oil (Phillips Petroleum, Borger, OK) and then spray inoculated onto the plants. After inoculation, seedlings were allowed to dry for $1 \mathrm{~h}$ and then placed in a mist chamber overnight at $18^{\circ} \mathrm{C}$ and $100 \%$ relative humidity. After incubation, the seedlings were placed on a greenhouse bench with supplemental metal halide lighting at a temperature of 18 to $23^{\circ} \mathrm{C}$. Seedlings were fertilized with a 20-2020 NPK solution immediately after inoculation and at 14 days after planting. The infection types (IT) on the primary leaves of individual plants were recorded 10 days after inoculation using a 0 to-4 scale, as detailed by Long and Kolmer (1989) and McIntosh et al. (1995). The most commonly expressed ITs in this study were IT $;=$ pinhead necrotic spots, IT $; 1=$ presence of pinhead necrotic spots (;) and some with small reddish dots (1) on the same leaf, and IT $3^{+}=$pustules showing sporulation (red powdery mass). The signs plus (+) and minus (-) were used to reflect ITs higher and lower than those expected for that class.
Evaluation against Australian P. triticina races. Six sets of eight seeds each of Aus26582, Aus26579, and Bansi were sown in 9-cm pots filled with a potting mix containing a mixture of pine bark and river sand at a ratio of 2:1. Water-soluble fertilizer Aquasol $(20 \mathrm{~g})$ dissolved in 10 liters of water was applied to all pots before sowing. The pots were placed in a rust-free microclimate room maintained at $20^{\circ} \mathrm{C}$. At 1 week after sowing, nitrogenous fertilizer urea was applied to all pots at the same rate as the Aquasol.

Inoculations were carried out at the two-leaf stage. Urediniospores of each pathotype (Table 1) were suspended in light mineral oil Isopar-L $(10 \mathrm{ml})$ and atomized using an aerosol pressure pack on each set separately, according to Bariana and McIntosh (1993). Inoculated seedlings were placed in a dark humid chamber fitted with an ultrasonic humidifier for $24 \mathrm{~h}$. After $24 \mathrm{~h}$, inoculated seedlings were transferred to microclimate rooms maintained at $25 \pm 2{ }^{\circ} \mathrm{C}$. Leaf rust response was recorded after 12 to 14 days of inoculation using the 0 -to-4 scale described in McIntosh et al. (1995). Both RIL populations were also tested against $P$. triticina race 104-1,(2),3,(6),(7),11,13 (547) using the above-mentioned procedure.

DNA extraction. Genomic DNA was extracted from 10-day old seedlings of both RIL populations along with the parents, following the procedure described by Bansal et al. (2014b). The quality of DNA was tested using a Nanodrop ND-1000 spectrophotometer (Nanodrop Technologies) and final dilutions of $30 \mathrm{ng} / \mu \mathrm{l}$ were prepared.

Genomic location of resistance genes. A DArTseq map of the Aus26582/Bansi RIL population containing 5,802 markers was available from another study pertaining to quantitative trait locus mapping of stripe rust resistance (U. Bansal and H. Bariana, unpublished). Phenotypic data were converted to genotypes and incorporated into the Aus26582/Bansi DArTseq map using MapManager, version QTXb20 (Manly et al. 2001). Previously reported SSR markers located in the short arm of chromosome 6B were also used (the GrainGenes 2.0 database; https://wheat.pw. usda.gov). Both RIL populations were tested with polymorphic markers.

Development of new SSR markers. Sequences of DArTseq markers that showed close linkage with the resistance gene were blasted against the flow-sorted chromosome survey sequence (CSS) contigs of Chinese Spring using BlastN query (https://urgi.versailles.inra.fr/ blast/?dbgroup=wheat_all\&program=blastn). The CSS contigs having $100 \%$ similarity $\left(1 \mathrm{e}^{-28}\right.$ to $\left.5 \mathrm{e}^{-08}\right)$ were selected and used to design SSR markers using the BatchPrimer3 software (http://batchprimer3. bioinformatics.ucdavis.edu/cgi-bin/batchprimer3/batchprimer3.cgi). Each forward primer had an M13 sequence tail added to it at the 5' end. These primers were named as "sun" (Sydney University) and sequences are given in Table 2.

Development of kompetitive allele-specific polymerase chain reaction markers. The CSS contig 6BS_2963854 (from which closely linked SSR markers were identified) was used to develop sequence-tagged site (STS) markers in order to identify singlenucleotide polymorphisms (SNPs) between the parents Aus26582 and Bansi. Primers were designed using software Primer3 (v. 0.4.0) (Koressaar and Remm 2007; Untergasser et al. 2012). Majority

TABLE 1. Virulence/avirulence formulae of Puccinia triticina races used

\begin{tabular}{|c|c|c|}
\hline Leaf rust pathotype & Culture number & Virulence/avirulence formula ${ }^{a}$ \\
\hline $104-2,3,6,(7)$ & 231 & Lr14a, (Lr17a), Lr17b, Lr23, Lr27+Lr31/Lr3ka, Lr13, Lr15, Lr16, Lr20, Lr24, Lr26, Lr28, Lr37, Lr61, Lr72 \\
\hline $10-1,2,3,4$ & 348 & Lr14a, Lr15, Lr20, Lr23/Lr3ka, Lr13, Lr16, Lr17a, Lr17b, Lr24, Lr27+Lr31, Lr26, Lr28, Lr37, Lr61, Lr72 \\
\hline $68-1,2,3,4$ & 469 & Lr14a, Lr15, Lr20, Lr23/Lr3a, Lr13, Lr16, Lr17a, Lr17b, Lr24, Lr26, Lr27+Lr31, Lr28, Lr37, Lr61, Lr72 \\
\hline $104-1,(2), 3,(6),(7),(9), 11,13+L r 24$ & 547 & Lr14a, Lr17a, Lr20, Lr23, Lr24, Lr26, Lr27+Lr31/ Lr3a, Lr13, Lr15, Lr17b, Lr28, Lr37, Lr61, Lr72 \\
\hline $76-1,3,5,7,9,10,12+L r 37$ & 621 & Lr13, Lr14a, Lr16, Lr17a, Lr17b, Lr20, Lr26, Lr371 Lr15, Lr23, Lr24, Lr28, Lr27+Lr31, Lr61, Lr72 \\
\hline $104-1,3,4,6,7,8,9,10,12+\operatorname{Lr} 37$ & 634 & Lr12, Lr13, Lr14a, Lr17a, Lr17b, Lr20, Lr26, Lr27+Lr31, Lr28, Lr37/Lr1, Lr3a, Lr16, Lr24, Lr23, Lr61, Lr72 \\
\hline CA 1.2 & & $\begin{array}{l}\text { Lr1, Lr2a, Lr2c, Lr3a, Lr3ka, Lr3bg, Lr9, Lr11, Lr14a, Lr16, Lr17a, Lr18, Lr21, Lr24, Lr26, Lr28, } \\
\quad \text { Lr30, Lr39, Lr42, Lr72/LrB, Lr10, Lr14b, Lr20, Lr23 }\end{array}$ \\
\hline ETH 12.5-2 & & Lr72-virulent and avirulent on Thatcher \\
\hline
\end{tabular}

a Taken from the University of Sydney Cereal Rust Collection database and Cereal Disease Laboratory database, United States. 
parameters used for designing primers were with default settings but minimum melting temperature was set to $57^{\circ} \mathrm{C}$ and maximum to $63^{\circ} \mathrm{C}$. The fragment length was set to 1,000 to $1,300 \mathrm{bp}$.

STS markers were used to amplify products from Aus26582 and Bansi and the amplicons were sequenced at the Australian Genomic Research Facility, Sydney (www.agrf.org.au) using the Sanger sequencing method. Sequences were aligned using the Sequencher software (www.genecodes.com). The SNP in the parental sequences were used to design kompetitive allele-specific polymerase chain reaction (KASP) markers using BatchPrimer3 v1.0 software (http:// batchprimer3.bioinformatics.ucdavis.edu/cgi-bin/batchprimer3/ batchprimer3.cgi). Each KASP marker was named as "sunKASP" followed by the consecutive number. KASP genotyping was performed according to Nsabiyera et al. (2016).

SSR and STS genotyping. Polymerase chain reaction (PCR) volumes of $10 \mu \mathrm{l}$ were used for SSR genotyping. The reaction mixture contained $30 \mathrm{ng}$ of genomic DNA, 1× Immolase buffer containing $1.5 \mathrm{mM} \mathrm{MgCl}_{2}, 200 \mathrm{mM}$ dNTP, $100 \mathrm{nM} \mathrm{M} 13$ tailed forward primer, $200 \mathrm{nM}$ reverse primer, $100 \mathrm{nM}$ M13 dye with labeled fluorescence (IR-700 or IR-800), and $0.04 \mathrm{U}$ of Immolase DNA polymerase (Bioline). PCR was performed using a touchdown profile comprising a initial denaturing step of $95^{\circ} \mathrm{C}$ for $10 \mathrm{~min}$ for the activation of DNA polymerase (Hot Start); followed by $92^{\circ} \mathrm{C}$ for $30 \mathrm{~s}, 62^{\circ} \mathrm{C}$ (with $1^{\circ} \mathrm{C}$ drop down for 7 cycles) for $30 \mathrm{~s}$, and $72^{\circ} \mathrm{C}$ for $30 \mathrm{~s} ; 35$ cycles of $30 \mathrm{~s}$ at $92^{\circ} \mathrm{C}, 30 \mathrm{~s}$ at $55^{\circ} \mathrm{C}$, and $30 \mathrm{~s}$ at $72^{\circ} \mathrm{C}$; and a final extension step at $72^{\circ} \mathrm{C}$ for $10 \mathrm{~min}$. PCR products were separated on $2 \%$ agarose gels. For smaller base pair differences, the products were separated on $6.5 \%$ polyacrylamide gels on a LICOR 4300 DNA analyzer (Bansal et al. 2014a).

For STS markers, $20 \mu \mathrm{l}$ of reaction volumes were used. The reaction mixture contained $30 \mathrm{ng}$ genomic DNA, $1 \times$ Immolase buffer containing $1.5 \mathrm{mM} \mathrm{MgCl} 2,200 \mathrm{mM}$ dNTP, $100 \mathrm{nM}$ forward primer, $200 \mathrm{nM}$ reverse primer, and $0.04 \mathrm{U}$ of Immolase DNA polymerase (Bioline). PCR was carried out using a touchdown profile comprising initial denaturation of $95^{\circ} \mathrm{C}$ for $10 \mathrm{~min}$; followed by 5 cycles of denaturation at $92^{\circ} \mathrm{C}$ for $30 \mathrm{~s}$, annealing at $65^{\circ} \mathrm{C}$ (with $1^{\circ} \mathrm{C}$ drop down for five cycles) for $40 \mathrm{~s}$, and extension at $72^{\circ} \mathrm{C}$ for $50 \mathrm{~s} ; 35$ cycles of $30 \mathrm{~s}$ at $92^{\circ} \mathrm{C}, 40 \mathrm{~s}$ at $60^{\circ} \mathrm{C}$, and $50 \mathrm{~s}$ at $72^{\circ} \mathrm{C}$; and a final extension step at $72^{\circ} \mathrm{C}$ for $5 \mathrm{~min}$. PCR products were eluted from $1 \%$ agarose gels.

Statistical analysis and linkage map construction. To determine the goodness of fit of the observed segregation to the expected genetic ratios, $\chi^{2}$ tests were performed on the phenotypic segregation data of RIL populations. A genetic linkage map was constructed using MapManager, version QTXb20 (Manly et al. 2001) and the final linkage maps were drawn using Map Chart, version 2.2 (Voorrips 2002).

\section{RESULTS}

Parental assessments and inheritance studies. Aus 26582 and Aus26579 produced IT ; (; = near immune) against durumspecific races CA 1.2 and ETH 12.5-2 when tested at the CDL, Minnesota, and the susceptible control Bansi produced IT $3^{+}$against both races. RIL populations were tested at the seedling stage against races CA 1.2 and ETH 12.5-2. The $\chi^{2}$ analysis of seedling leaf rust response variation among both RIL populations against races CA 1.2 and ETH 125.2 conformed to segregation at a single locus (Table 3). Homozygous resistant lines among both RIL populations produced IT ; to ; 1 similar to the resistant parents, and homozygous susceptible RILs displayed IT $3^{+}$, identical to the susceptible parent Bansi.

Aus26582 and Aus26579 displayed IT ; to ;1+ against six common wheat $P$. triticina races in Australia (Fig. 1). The Aus26579/Bansi RIL population showed results identical to those observed with races CA 1.2 and ETH 125.2 when tested against Australian $P$. triticina race 104-1,(2),3,(6),(7),11,13. In contrast, digenic $\left(118\left[\right.\right.$ IT $; 1$ to $\left.; 22^{+}\right]: 37\left[\right.$ IT $\left.3^{+}\right] ; \chi_{(3: 1)}^{2}=0.11$, nonsignificant at $P=0.05$ and 1 degree of freedom [df]) inheritance of leaf rust resistance was noted among the Aus26582/Bansi RIL population against $P$. triticina race 104-1,(2),3,(6),(7),11,13. Sixty-nine RILs that were scored homozygous susceptible (Table 3) against the durum-specific races showed monogenic inheritance when tested against 104-1,(2),3,(6),(7),11,13 (32 [IT 12- to ;22+]:37 [IT 3+]; $\chi_{(1: 1)}^{2}=0.36$, nonsignificant at $P=0.05$ and $\left.1 \mathrm{df}\right)$. The second locus in Aus26582 was ineffective against durum-specific races. This investigation covers results on characterization of the locus conferring resistance to durum-specific races segregating in both RIL populations. The locus conferring leaf rust resistance in Aus26582 against

TABLE 3. Frequency distribution of Aus26582/Bansi and Aus26579/Bansi recombinant inbred lines (RILs) when tested against durum-specific Puccinia triticina races CA 1.2 and ETH $125-2$

\begin{tabular}{llccc}
\hline \multirow{2}{*}{ Population } & & \multicolumn{2}{c}{ Number of RIL } & \\
\cline { 3 - 3 } Aus26582/Bansi & Phenotype & Observed & Expected & $\chi_{(1: 1)}^{2}{ }^{\mathrm{a}}$ \\
& Resistant & 86 & 77.5 & 0.93 \\
& Susceptible & 69 & 77.5 & 0.93 \\
Aus26579/Bansi & Total & 155 & 155.0 & 1.86 \\
& Resistant & 38 & 39.5 & 0.06 \\
& Susceptible & 41 & 39.5 & 0.06 \\
& Total & 79 & 79.0 & 0.12 \\
\hline
\end{tabular}

a Table value of $\chi^{2}$ at $P=0.05$ and 1 degree of freedom $=3.84$.

TABLE 2. Polymerase chain reaction-based markers developed in this study from the DArTseq marker sequences

\begin{tabular}{|c|c|c|c|c|c|c|c|c|c|}
\hline \multirow[b]{2}{*}{ DArTseq marker } & \multirow[b]{2}{*}{$\operatorname{Loc}(\mathrm{cM})^{\mathrm{a}}$} & \multirow[b]{2}{*}{$\mathrm{CSS}^{\mathrm{b}}$ contig } & \multirow[b]{2}{*}{ E-value } & \multirow[b]{2}{*}{ Repeat motif } & \multirow[b]{2}{*}{ Marker name } & \multirow[b]{2}{*}{ Primer $\left(5^{\prime}-3^{\prime}\right)$} & \multicolumn{3}{|c|}{ Amplicon (bp) } \\
\hline & & & & & & & Aus26582 & Aus26579 & Bansi \\
\hline 1089713 & 5.78 & 6BS_3028198 & $1 e-28$ & $(\mathrm{TC})^{13}$ & $\begin{array}{l}\operatorname{sun} 677-F^{\mathrm{c}} \\
\operatorname{sun} 677-R\end{array}$ & $\begin{array}{l}\text { tcgattaaatgaaaccagaac } \\
\text { agggagagagaaacttgctta }\end{array}$ & 151 & 151 & Null \\
\hline 1725149 & 6.45 & 6BS_2935897 & $1 e-22$ & $(\text { TGAGAC) })^{3}$ & $\begin{array}{l}\text { sun678-F } \\
\text { sun678-R }\end{array}$ & $\begin{array}{l}\text { gtgttggtaaagcaagactga } \\
\text { ttgatcatttgaaagatgtgac }\end{array}$ & 146 & 146 & 146 \\
\hline 3024107 & 6.86 & 6BS_2938796 & $2 e-13$ & $(\mathrm{ATGC})^{3}$ & $\begin{array}{l}\text { sun679-F } \\
\text { sun679-R }\end{array}$ & $\begin{array}{l}\text { tgctagatcggtttgattcta } \\
\text { agtgagcaagttacaacacg }\end{array}$ & Null & Null & 162 \\
\hline $3939152^{d}$ & 6.86 & 6BS_2996377 & $2 e-06$ & $(\mathrm{TGA})^{4}$ & $\begin{array}{l}\text { sun680-F } \\
\text { sun680-R }\end{array}$ & $\begin{array}{l}\text { tgttattcccactatgaccag } \\
\text { tatttagaaacggagggagtc }\end{array}$ & 142 & 142 & 142 \\
\hline & & & & $\begin{array}{l}(\mathrm{TTCTT})^{3} \\
(\mathrm{CCACA})^{4}\end{array}$ & $\begin{array}{l}\text { sun681-F } \\
\text { sun681-R } \\
\text { sun682-F } \\
\text { sun682-R }\end{array}$ & $\begin{array}{l}\text { ctgtcetgttttgtttgtttc } \\
\text { agaaacgtgaacaagtttgaa } \\
\text { ctctctttctcgttactgctg } \\
\text { ggtttgggagtaagaatgttt }\end{array}$ & 180 & 180 & 180 \\
\hline $4261696^{\mathrm{d}}$ & 6.86 & 6BS_2963854 & $5 e-08$ & $(\mathrm{CTG})^{4}$ & $\begin{array}{l}\text { sun683-F } \\
\text { sun683-R }\end{array}$ & $\begin{array}{l}\text { gacgttcaaaaagttgaaaag } \\
\text { aacctctagacacaaatgcaa }\end{array}$ & 160 & Null & Null \\
\hline & & & & $(\mathrm{ATGG})^{3}$ & $\begin{array}{l}\text { sun684-F } \\
\text { sun684- } R\end{array}$ & $\begin{array}{l}\text { cgttcgttttctatcgtttta } \\
\text { ggttatccatgtgattcaaga }\end{array}$ & 124 & 124 & 128 \\
\hline
\end{tabular}

\footnotetext{
a Map location in centimorgans (cM).

b $\mathrm{CSS}=$ chromosome survey sequence.

c Forward primer labeled with M13: CACGACGTTGTAAAACGAC.

d Position not available in DArTseq map but cosegregated with 6BS_2938796.
} 
durum-specific pathotypes was temporarily named $\operatorname{LrAW} 2$ and the DArTseq map of Aus26582/Bansi RIL population was used for genomic location of this resistance locus.

Genomic location of $\boldsymbol{L r} \boldsymbol{A W}$. The DArTseq linkage map of 92 Aus26582/Bansi RIL (U. Bansal and H. Bariana, unpublished results) covering 14 linkage groups assigned to all 14 chromosomes with 5,802 markers was used to determine genomic location of location of $L r A W 2$. Because the Aus26582/Bansi RIL population exhibited monogenic segregation for $L r A W 2$ (Table 3), the phenotypic segregation data were converted into genotypes: $\angle r A W 2=\mathrm{A}$ and $l r A W 2=\mathrm{B}$ and LrAW2 was incorporated into the DArTseq linkage map using the MapManager program (version QTXb20) through the link report function. LrAW2 was mapped in the 3.1-centimorgan (cM) marker interval flanked by markers 1270844 to 7914776 in the short arm of chromosome 6B (Fig. 2A) and five DArTseq markers (1089713, $1725149,3024107,3939152$, and 4261696) cosegregated with $L r A W 2$ $\left(R^{2}=15 \%\right)$. The sequences of DArTseq markers 1089713, 1725149, 3024107, 3939152, and 4261696 showed homology with the CSS contigs 6BS_3028198, 6BS_2935897, 6BS_2938796, 6BS_2996377, and 6BS_2963854, respectively, when BlastN searched against the flow-sorted chromosome 6B sequence of the reference wheat 'Chinese Spring' (Table 2). Eight SSR markers designed from the CSS contigs listed in Table 2 were tested for polymorphism on parental genotypes. Five SSR markers (sun677, sun679, sun682, sun683, and sun684) showed polymorphisms between Aus26582 and Bansi. Marker sun679 did not amplify any product in Aus26582, whereas Bansi was null for markers sun677, sun682, and sun683. Three markers (sun677, sun682, and sun684) were polymorphic between Aus26579 and Bansi.

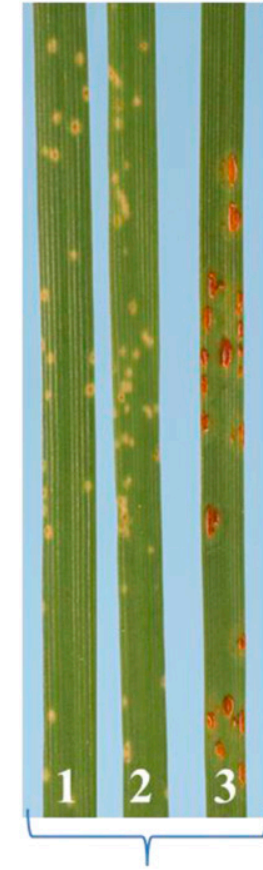

$104-2,3,6,(7)$

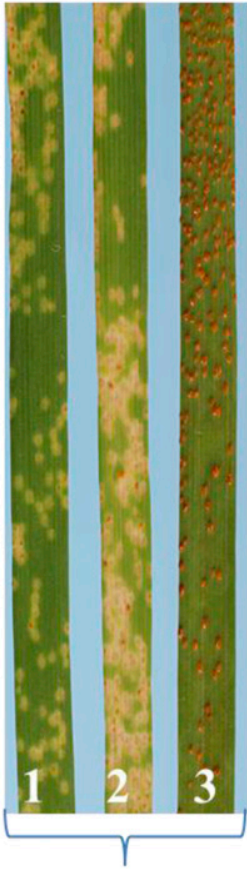

$10-1,2,3,4$



$68-1,2,3,4$

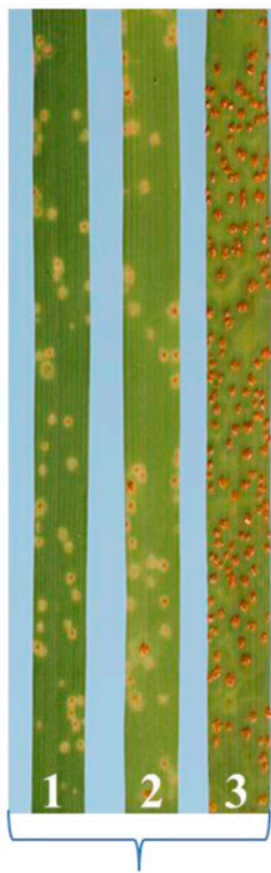

104-1,(2),3,(6),(7), (9),11,13+Lr24
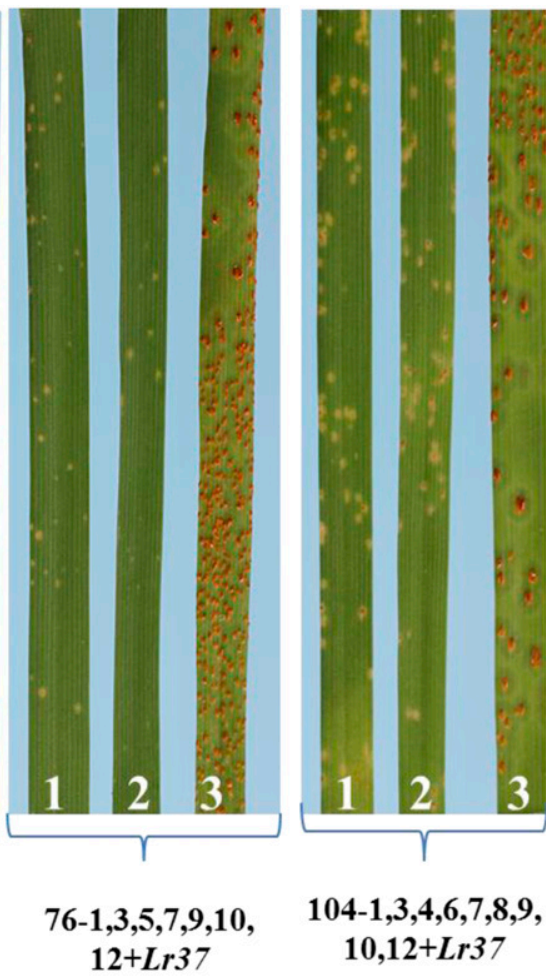

104-1,3,4,6,7,8,9, $10,12+\operatorname{Lr} 37$

Fig. 1. Infection types produced by Aus26582 (lane 1), Aus26579 (lane 2), and Bansi (lane 3) against six common wheat Puccinia triticina pathotypes.

A

Aus26582/Bansi

(92 RILs)
B

Aus26582/Bansi

(155 RILs)
C

Aus26579/Bansi

(79 RILs)

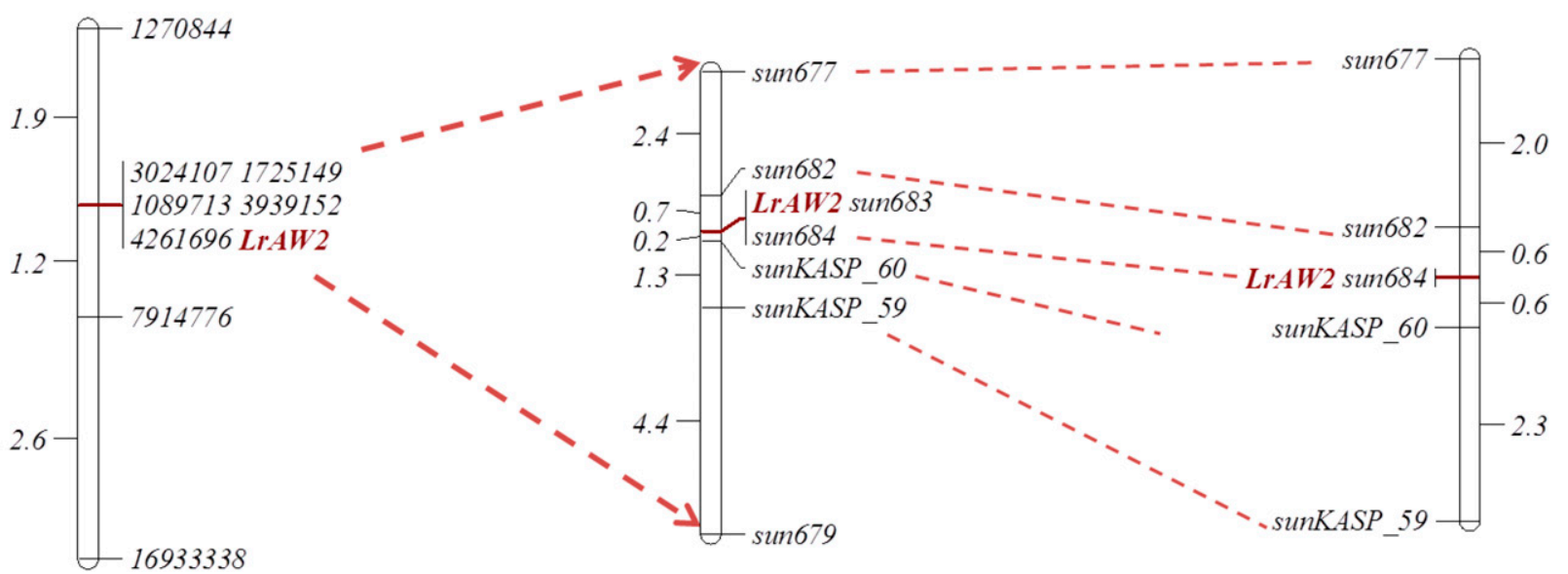

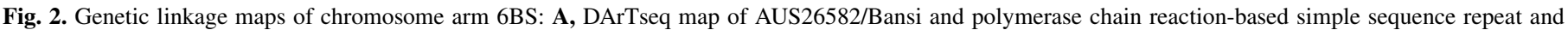
single-nucleotide polymorphism marker maps of B, Aus26582/Bansi and C, Aus26579/Bansi RIL populations showing the location of LrAW2. 
Markers sun683 and sun684 (designed from the CSS contig 6BS2963854) cosegregated with $L r A W 2$ in the Aus26582/Bansi population (Fig. 2B), whereas only sun684 cosegregated with LrAW2 in the Aus26579/ Bansi population (Fig. 2C). Marker sun682 mapped 0.7 and $0.6 \mathrm{cM}$ distal to $L r A W 2$ in Aus26582/Bansi and Aus26579/Bansi RIL populations, respectively (Fig. 2B and C). These results indicated presence of the same gene for leaf rust resistance in Aus26582 and Aus26579.

Five overlapping STS markers (sun665, sun666, sun667, sun668, and sun669) were designed from the CSS contig 6BS_2963854 (Table 4; Fig. 3). Three of the five markers (sun667, sun668, and sun669) produced $>1-\mathrm{kb}$ amplicons, whereas two markers (sun665 and sun666) produced multiple bands in parental genotypes Aus26582 and Bansi. The amplicons produced by three markers (sun667, sun668, and sun669) in Aus26582 and Bansi were sequenced, aligned, and compared for SNP. No polymorphism was observed between the sequences of parental amplicons of marker sun668, whereas one and four SNP were observed in amplicons produced by sun667 and sun669,

TABLE 4. List of sequence-tagged site markers designed from the chromosome survey sequence contig 6BS_2963854

\begin{tabular}{|c|c|c|}
\hline Marker name & Primer sequence $\left(5^{\prime}-3^{\prime}\right)$ & Product size (bp) \\
\hline sun665-F & tggcaagcaagttgtcactc & 1,400 \\
\hline $\operatorname{sun} 665-R$ & gecatactgatgccaaaggt & \\
\hline sun666- $F$ & ttccactatatccagcgtcgt & 1,212 \\
\hline sun666-R & gaccetgccgttactcacc & \\
\hline sun667-F & atcggacgaggatttgtgac & 1,283 \\
\hline sun667-R & ggaacgtcttcctgacgtgt & \\
\hline sun668-F & tagaagggtggggtgctaga & 1,267 \\
\hline sun668-R & gctctgacgatgtcgcaata & \\
\hline sun669-F & tattgcgacatcgtcagagc & 1,288 \\
\hline sun669-R & gacacgtcgatccggtactt & \\
\hline
\end{tabular}

respectively. Five allele-specific primers sunKASP_57 (sun667), sunKASP_58, sunKASP_59, sunKASP_60, and sunKASP_61 (sun669) were developed (Table 5; Fig. 3). These markers were tested on the parents to check allele clustering. Two markers, sunKASP_59 and sunKASP_60, produced well-differentiated clusters and were tested on both RIL populations and incorporated into the map.

SSR markers previously reported on the short arm of chromosome 6B were also used. Markers wmc487, gwm133, gwm193, and cfdl3 showed polymorphism among three parental genotypes but did not show association with LrAW2 in both RIL populations. The linkage maps of the $L r A W 2$ region included seven markers (five SSR and two KASP) in the Aus26582/Bansi and five markers (three SSR and two KASP) in the Aus26579/Bansi population (Fig. 2). Marker sunKASP_60 was mapped 0.2 and $0.6 \mathrm{cM}$ proximal to $L r A W 2$, whereas sunKASP_59 was mapped 1.5 and $2.9 \mathrm{cM}$ proximal to LrAW2 in Aus26582/Bansi and Aus26579/Bansi RIL populations, respectively.

Validation of $\mathbf{L r A W 2}$-linked markers. Markers sun683, sun684, and sunKASP_60 were genotyped on 11 Australian durum cultivars (Table 6). All of these cultivars were susceptible to the race CA 1.2 and produced amplicons or haplotypes different from those associated with $L r A W 2$ for three markers. These results indicated the effectiveness of markers sun683, sun684, and sunKASP_60 for MAS of LrAW2 in durum breeding programs.

\section{DISCUSSION}

Although Australia is geographically separated from all other wheatgrowing continents, incursions of exotic rust races have occurred (Kolmer 2005; Park et al. 2002; O'Brien et al. 1980; Wellings et al. 2003). The two separate detections of $P$. striiformis $\mathrm{f}$. sp. tritici (causal organism of wheat stripe rust) in 1979 in eastern Australia (O'Brien et al. 1980) and in 2002

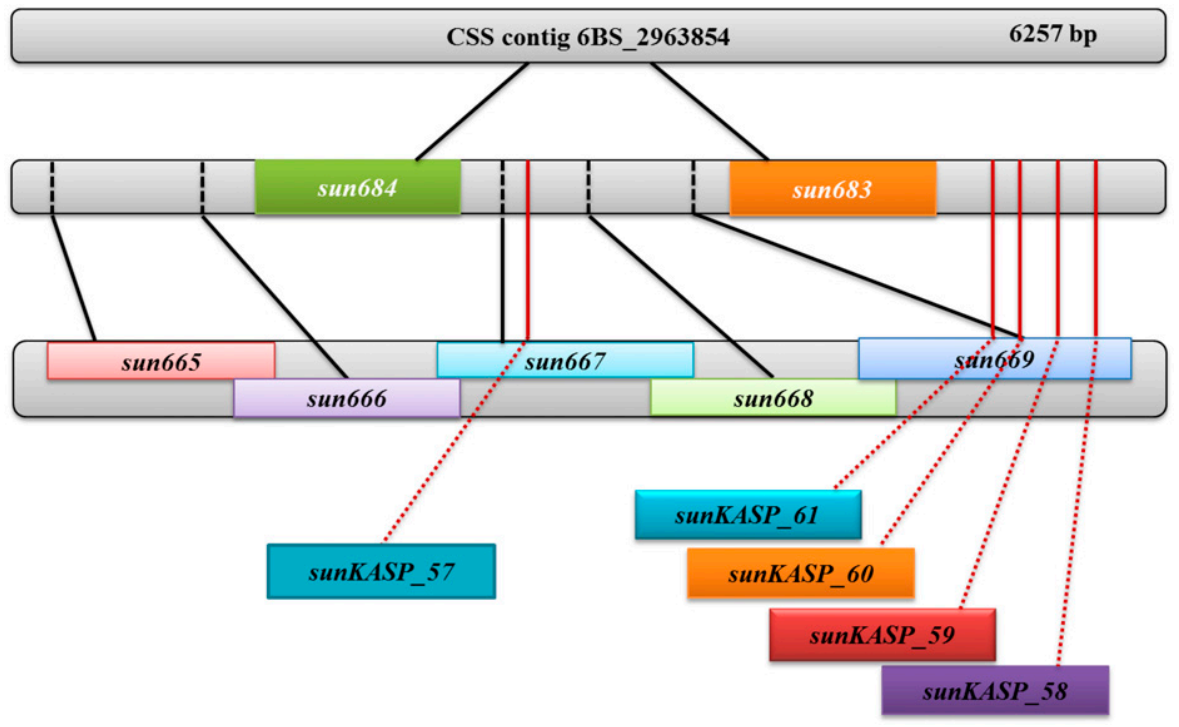

Fig. 3. Graphical presentation of simple sequence repeat, sequence-tagged site, and kompetitive allele-specific polymerase chain reaction (KASP) markers developed from the chromosome survey sequence (CSS) contig 6BS_2963854.

TABLE 5. Development of kompetitive allele-specific polymerase chain reaction (KASP) assays from the single-nucleotide polymorphisms (SNP) detected between the parental sequences

\begin{tabular}{|c|c|c|c|c|c|}
\hline STS marker ${ }^{\mathrm{a}}$ & Marker name & Allele 1 primer $^{b}$ & Allele 2 primer $^{\mathrm{c}}$ & Common primer & SNP \\
\hline sun667 & sunKASP_57 & ctactaaagactccacaaaccacaa & ctactaaagactccacaaaccacac & gccgtagcagtccattgaag & {$[\mathrm{A} / \mathrm{C}]$} \\
\hline $\operatorname{sun} 669$ & sunKASP_58 & ccctctacaacaccataattgg & gccetctacaacaccataattga & tttatacgggtgccatggtt & {$[\mathrm{G} / \mathrm{A}]$} \\
\hline sun669 & sunKASP_59 & gctccaccaattctacatctga & gctccaccaattctacatctgc & atgaggetggggtaggagag & {$[\mathrm{A} / \mathrm{C}]$} \\
\hline sun669 & sunKASP_60 & cactgaagcttgccggat & cactgaagcttgccggac & ggatgatatcgtcgggtagg & {$[\mathrm{T} / \mathrm{C}]$} \\
\hline sun669 & sunKASP_61 & ctatgcgcgtcetgtgg & gctatgcgcgtcctgtgt & cattggcaccaacttataaatca & {$[\mathrm{T} / \mathrm{G}]$} \\
\hline
\end{tabular}

a STS = sequence-tagged site.

b A1 primer labeled with FAM: GAAGGTGACCAAGTTCATGCT.

c A2 primer labeled with HEX: GAAGGTCGGAGTCAACGGATT. 



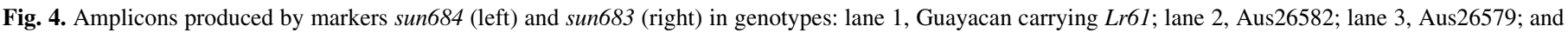
lane 4, the susceptible control Bansi; lane L = 1-kb DNA ladder (right).

TABLE 6. Validation of markers closely linked with LrAW2 among Australian durum wheat cultivars

\begin{tabular}{lcccc}
\hline Australian wheat & IT $(\text { CA } 1.2)^{\mathrm{a}}$ & $\begin{array}{c}\text { sun684 } \\
(\mathrm{bp})\end{array}$ & $\begin{array}{c}\text { sun683 } \\
(\mathrm{bp})\end{array}$ & sunKASP_60 \\
\hline Aus26582, & $;$ & 124 & 160 & $\mathrm{~T}: \mathrm{T}$ \\
$\quad$ Aus26579 & $3+$ & 128 & Null & C:C \\
Bansi & $3+$ & 128 & Null & C:C \\
Bellaroi & $3+$ & 128 & Null & C:C \\
Kalka & $3+$ & 128 & Null & C:C \\
Arrivato & $3+$ & 128 & Null & C:C \\
Caparoi & Not tested & 128 & Null & C:C \\
DBA-Aurora & $3+$ & 128 & Null & C:C \\
Gundaroi & $3+$ & 128 & Null & C:C \\
Jandaroi & $3+$ & 128 & Null & C:C \\
Tjilkuri & $3+$ & 128 & Null & C:C \\
Tamaroi & $3+$ & 128 & Null & C:C \\
WID802 & $3+$ & 128 & Null & C:C \\
Wollaroi & & & & \\
\hline
\end{tabular}

a Infection type.

in Western Australia, arguably from two different geographic regions (Wellings et al. 2003), clearly show the international spread of rust pathogens and, hence, the introduction of durum-specific $P$. triticina races is perhaps only a matter of time. Current Australian durum wheat cultivars are resistant to all prevalent Australian P. triticina races and are susceptible to durum-specific races of Mexico and Ethiopia $(\mathrm{H}$. Bariana and U. Bansal, unpublished).

Transfer of genetic variation from landraces and wild relatives is crucial to increase genetic diversity among modern wheat germplasm (Bariana et al. 2013; Randhawa et al. 2014; Soriano et al. 2016). Aus26582 and Aus26579 selected in this study appeared to carry the same gene $(L r A W 2)$ for resistance to $P$. triticina races CA 1.2 and ETH 12.5-2 based on molecular mapping results and their effectiveness against durum-specific $P$. triticina races. The closely linked markers sun683 (dominant), sun684 (codominant), and sunKASP_60, developed in this study, will facilitate MAS of $L r A W 2$ to prepare against the introduction of durum-specific races in Australia and other nations.

Leaf rust resistance gene $\operatorname{Lr61}$ has also been mapped in the chromosome 6BS of a Chilean wheat 'Guayacan INIA' (Guayacan) by Herrera-Foessel et al. (2008) using amplified fragment length polymorphism (AFLP) markers. Guayacan produces low IT ; 1 to ;12 against Mexican P. triticina races BBG/BN, NCJ/BN, and $\mathrm{MCJ} /$ $\mathrm{SP}$ and $\mathrm{X}^{+}$against the race $\mathrm{BBB} / \mathrm{BN}$. The use of AFLP markers for mapping Lr61 and DArTseq-derived markers in the current study did not allow a direct comparison of map locations in these investigations. Markers sun683, sun684, and sunKASP_60 were tested on Guayacan (DNA kindly provided by Dr. Mandeep Randhawa, CIMMYT INT, Mexico). Guayacan produced amplicons or haplotypes similar to Aus26582 and Aus26579 (Fig. 4), suggesting that $L r A W 2$ and $L r 61$ may represent the same locus; however, the possibility of either close linkage or the allelic relationship between these genes cannot be ignored. $\operatorname{Lr61}$ was effective against prevalent durum-specific Mexican $P$. triticina races, except a variant of an old race, BBB/BN (Herrera-Foessel et al. 2014), and it is still effective against European and Ethiopian races and the durumspecific $P$. triticina races from the United States. Tests on Aus26582 and Aus26579 against six Australian common wheat $P$. triticina races also suggested its effectiveness in Australia. No durum-specific P. triticina race has yet been detected in Australia; however, previous incursions of foreign races of all three rust pathogens in Australia (O'Brien et al. 1980; Park 2007; Park et al. 2002; Wellings et al. 2003) stress the need to perform anticipatory breeding for resistance against durum-specific races.

LrAW2 is not present in any of the current Australian durum wheat cultivars. All Australian durum cultivars carried sun683, sun684, and sunKASP_60 alleles alternate to those linked with $L r A W 2$, indicating their effectiveness for MAS. Leaf rust resistance genes $L r 23$ and $L r W o$, present either singly or in combination in some Australian durum wheat cultivars, are effective against predominant common wheat $P$. triticina races in Australia. The adult plant resistance gene $L r 46$ is also present in some Australian durum wheat cultivars (U. Bansal and H. Bariana, unpublished). Markers closely linked with $L r A W 2$ will be useful in its pyramiding with other markertagged resistance genes for preemptive breeding against the durumspecific races in Australia and elsewhere. Overall, markers developed in this study will be useful for both low-throughput (SSR) prebreeding and high-throughput (SNP) commercial breeding programs.

\section{ACKNOWLEDGMENTS}

N. Qureshi acknowledges the University of Sydney for the USydIS award to pursue her Ph.D. studies. We thank the Grains Research and Development Corporation (GRDC) Australia for financial support through the Australian Cereal Rust Control Program. All authors read the manuscript and there is no conflict of interest.

\section{LITERATURE CITED}

Bansal, U., Arief, V. N., DeLacy, I. H., and Bariana, H. S. 2013. Exploring wheat landraces for rust resistance using a single marker scan. Euphytica 194:219-233.

Bansal, U., Bariana, H., Wong, D., Randhawa, M., Wicker, T., Hayden, M., and Keller, B. 2014a. Molecular mapping of an adult plant stem rust resistance gene Sr56 in winter wheat cultivar Arina. Theor. Appl. Genet. 127: 1441-1448.

Bansal, U. K., Kazi, A. G., Singh, B., Hare, R. A., and Bariana, H. S. 2014b. Mapping of durable stripe rust resistance in a durum wheat cultivar Wollaroi. Mol. Breed. 33:51-59.

Bariana, H. S., Bansal, U. K., Basandrai, D., and Chhetri, M. 2013. Disease resistance. Pages 291-314 in: Genomics and Breeding for Climate Resilient Crops. Vol. 2, Target Traits. Springer-Verlag, Berlin, Germany.

Bariana, H. S., and McIntosh, R. A. 1993. Cytogenetic studies in wheat. XV. Location of rust resistance genes in VPM1 and their genetic linkage with other disease resistance genes in chromosome 2A. Genome 36:476-482. 
Browder, L. E. 1980. A compendium of information about named genes for low reaction to Puccinia recondita in wheat. Crop Sci. 20:775-779.

Chhetri, M., Bariana, H., Wong, D., Sohail, Y., Hayden, M., and Bansal, U. 2017. Development of robust molecular markers for marker-assisted selection of leaf rust resistance gene Lr23 in common and durum wheat breeding programs. Mol. Breed. 37:21

Dyck, P. L., and Samborski, D. J. 1970. The genetics of two alleles for leaf rust resistance at the Lr14 locus in wheat. Can. J. Genet. Cytol. 12:689-694.

Goyeau, H., Berder, J., Czerepak, C., Gautier, A., Lanen, C., and Lannou, C. 2012. Low diversity and fast evolution in the population of Puccinia triticina causing durum wheat leaf rust in France from 1999 to 2009, as revealed by an adapted differential set. Plant Pathol. 61:761-772.

Goyeau, H., Park, R., Schaeffer, B., and Lannou, C. 2006. Distribution of pathotypes with regard to host cultivars in French wheat leaf rust populations. Phytopathology 96:264-273.

Henkrar, F., El-Haddoury, J., Ouabbou, H., Nsarellah, N., Iraqi, D., Bendaou, N., and Udupa, S. M. 2016. Genetic diversity reduction in improved durum wheat cultivars of Morocco as revealed by microsatellite markers. Sci. Agric. 73:134-141.

Herrera-Foessel, S., Huerta-Espino, J., Calvo-Salazar, V., Lan, C., and Singh, R. 2014. Lr72 confers resistance to leaf rust in durum wheat cultivar Atil C2000. Plant Dis. 98:631-635.

Herrera-Foessel, S., Singh, R., Huerta-Espino, J., Crossa, J., Yuen, J., and Djurle, A. 2006. Effect of leaf rust on grain yield and yield traits of durum wheats with race-specific and slow-rusting resistance to leaf rust. Plant Dis. 90:1065-1072.

Herrera-Foessel, S., Singh, R., Huerta-Espino, J., William, H., Djurle, A., and Yuen, J. 2008. Molecular mapping of a leaf rust resistance gene on the short arm of chromosome 6B of durum wheat. Plant Dis. 92:1650-1654.

Herrera-Foessel, S. A., Singh, R. P., Huerta-Espino, J., William, M., Rosewarne, G., Djurle, A., and Yuen, J. 2007. Identification and mapping of and a linked leaf rust resistance gene in durum wheat. Crop Sci. 47:1459-1466.

Kolmer, J., and Hughes, M. 2014. Physiologic specialization of Puccinia triticina on wheat in the United States in 2012. Plant Dis. 98:1145-1150.

Kolmer, J., Jin, Y., and Long, D. 2007. Wheat leaf and stem rust in the United States. Crop Pasture Sci. 58:631-638.

Kolmer, J. A. 2005. Tracking wheat rust on a continental scale. Curr. Opin. Plant Biol. 8:441-449.

Kolmer, J. A., and Acevedo, M. A. 2016. Genetically divergent types of the wheat leaf rust fungus Puccinia triticina in Ethiopia, a center of tetraploid wheat diversity. Phytopathology 106:380-385.

Koressaar, T., and Remm, M. 2007. Enhancements and modifications of primer design program Primer3. Bioinformatics 23:1289-1291.

Loladze, A., Kthiri, D., Pozniak, C., and Ammar, K. 2014. Genetic analysis of leaf rust resistance in six durum wheat genotypes. Phytopathology 104: $1322-1328$.

Long, D. L., and Kolmer, J. A. 1989. A North American system of nomenclature for Puccinia recondita f. sp. tritici. Phytopathology 79:525-529.

Lopes, M. S., El-Basyoni, I., Baenziger, P. S., Singh, S., Royo, C., Ozbek, K., Aktas, H., Ozer, E., Ozdemir, F., and Manickavelu, A. 2015. Exploiting genetic diversity from landraces in wheat breeding for adaptation to climate change. J. Exp. Bot. 66:3477-3486.

Manly, K. F., Cudmore, R. H., Jr., and Meer, J. M. 2001. Map Manager QTX, cross-platform software for genetic mapping. Mamm. Genome 12:930-932.

Martinez, F., Sillero, J., and Rubiales, D. 2005. Pathogenic specialization of Puccinia triticina in Andalusia from 1998 to 2000. J. Phytopathol. 153: 344-349.
McIntosh, R. A., Dubcovsky, J., Rogers, J. W., Morris, C., Appels, R., and Xia, C. X. 2014. Catalogue of gene symbols for wheat: 2013-2014 supplement. Online publication. KOMUGI Integrated Wheat Science Database. https:// shigen.nig.ac.jp/wheat/komugi/genes/macgene/supplement2013.pdf

McIntosh, R. A., Wellings, C. R., and Park, R. F. 1995. Wheat Rusts: An Atlas of Resistance Genes. CSIRO Publishing, East Melbourne, Australia.

McIntosh, R. A., Yamazaki, Y., Dubcovsky, J., Rogers, W., Morris, C., Appels, R., and Xia, X. C. 2013. Catalogue of gene symbols for wheat. In: Proceedings of the 12th International wheat genetics symposium, Yokohama, Japan.

Miller, T. E., Reader, S. M., and Ambrose, M. J. 2000. The Watkins wheat collection. Annu. Wheat Newsl. 46:172.

Nsabiyera, V., Qureshi, N., Bariana, H. S., Wong, D., Forrest, K. L., Hayden, M. J., and Bansal, U. K. 2016. Molecular markers for adult plant leaf rust resistance gene $L r 48$ in wheat. Mol. Breed. 36:65.

O’Brien, L., Brown, J., Young, R., and Pascoe, I. 1980. Occurrence and distribution of wheat stripe rust in Victoria and susceptibility of commercial wheat cultivars. Australas. Plant Pathol. 9:14.

Ordoñez, M., and Kolmer, J. 2007a. Virulence phenotypes of a worldwide collection of Puccinia triticina from durum wheat. Phytopathology 97: 344-351.

Ordoñez, M., and Kolmer, J. 2007b. Simple sequence repeat diversity of a worldwide collection of Puccinia triticina from durum wheat. Phytopathology 97:574-583.

Park, R. 2007. Stem rust of wheat in Australia. Crop Pasture Sci. 58:558-566.

Park, R., Bariana, H., Wellings, C., and Wallwork, H. 2002. Detection and occurrence of a new pathotype of Puccinia triticina with virulence for Lr24 in Australia. Crop Pasture Sci. 53:1069-1076.

Randhawa, M., Bansal, U., Valarik, M., Klocova, B., Dolezel, J., and Bariana, H. 2014. Molecular mapping of stripe rust resistance gene Yr51 in chromosome 4AL of wheat. Theor. Appl. Genet. 127:317-324.

Singh, B., Bansal, U. K., Forrest, K. L., Hayden, M. J., Hare, R. A., and Bariana, H. S. 2010. Inheritance and chromosome location of leaf rust resistance in durum wheat cultivar Wollaroi. Euphytica 175:351-355.

Singh, R., Bechere, E., and Abdalla, O. 1993. Genetic analysis of resistance to leaf rust in nine durum wheats. Plant Dis. 77:460-463.

Singh, R., Huerta-Espino, J., Pfeiffer, W., and Figueroa-Lopez, P. 2004. Occurrence and impact of a new leaf rust race on durum wheat in northwestern Mexico from 2001 to 2003. Plant Dis. 88:703-708.

Singh, R., and McIntosh, R. 1984. Complementary genes for reaction to Puccinia recondita tritici in Triticum aestivum. I. Genetic and linkage studies. Can. J. Genet. Cytol. 26:723-735.

Soriano, J. M., Villegas, D., Aranzana, M. J., del Moral, L. F. G., and Royo, C. 2016. Genetic structure of modern durum wheat cultivars and Mediterranean landraces matches with their agronomic performance. PLoS One 11: e0160983.

Untergasser, A., Cutcutache, I., Koressaar, T., Ye, J., Faircloth, B. C., Remm, M., and Rozen, S. G. 2012. Primer3-New capabilities and interfaces. Nucleic Acids Res. 40:e115.

Voorrips, R. E. 2002. MapChart: Software for the graphical presentation of linkage maps and QTLs. J. Hered. 93:77-78.

Watson, I., and Luig, N. 1961. Leaf rust on wheat in Australia: A systematic scheme for the classification of strains. Proc. Linnean Soc. New South Wales 86:241-250.

Wellings, C. R., Wright, D. G., Keiper, F., and Loughman, R. 2003. First detection of wheat stripe rust in Western Australia: Evidence for a foreign incursion. Australas. Plant Pathol. 32:321-322. 